\title{
Tackling Acute Lymphoblastic Leukemia-One Fish at a Time
}

\author{
Arpan A. Sinha ${ }^{1}$, Gilseung Park ${ }^{1,2}$ and J. Kimble Frazer ${ }^{1, *(1)}$ \\ 1 Jimmy Everest Section of Pediatric Hematology-Oncology, Department of Pediatrics, \\ University of Oklahoma Health Sciences Center, Oklahoma City, OK 73104, USA; \\ Arpan-Sinha@ouhsc.edu (A.A.S.); Gilseung-Park@ouhsc.edu (G.P.) \\ 2 Department of Cell Biology, University of Oklahoma Health Sciences Center, Oklahoma City, OK 73104, USA \\ * Correspondence: John-Frazer@ouhsc.edu; Tel.: +1-405-271-5311
}

Received: 8 October 2019; Accepted: 23 October 2019; Published: 25 October 2019

check for updates

\begin{abstract}
Despite advancements in the diagnosis and treatment of acute lymphoblastic leukemia (ALL), a need for improved strategies to decrease morbidity and improve cure rates in relapsed/refractory ALL still exists. Such approaches include the identification and implementation of novel targeted combination regimens, and more precise upfront patient risk stratification to guide therapy. New curative strategies rely on an understanding of the pathobiology that derives from systematically dissecting each cancer's genetic and molecular landscape. Zebrafish models provide a powerful system to simulate human diseases, including leukemias and ALL specifically. They are also an invaluable tool for genetic manipulation, in vivo studies, and drug discovery. Here, we highlight and summarize contributions made by several zebrafish T-ALL models and newer zebrafish B-ALL models in translating the underlying genetic and molecular mechanisms operative in ALL, and also highlight their potential utility for drug discovery. These models have laid the groundwork for increasing our understanding of the molecular basis of ALL to further translational and clinical research endeavors that seek to improve outcomes in this important cancer.
\end{abstract}

Keywords: leukemia; B-ALL; T-ALL; zebrafish; MYC; leukemia models

\section{Introduction}

The word "Leukemia" was coined from German, and derives from the Greek words "leukos", meaning white + "haima", meaning blood. Leukemias are cancers of white blood cells, and based on their cell of origin, are divided into leukemias of lymphoid/lymphocytic or myeloid/myelocytic origin. Based on their rate of clinical progression, they are categorized as either acute or chronic. This schema results in four broad leukemia classifications_acute lymphoid/lymphoblastic leukemia (ALL); acute myeloid/myelogenous leukemia (AML); chronic lymphocytic leukemia (CLL); and chronic myeloid/myelocytic leukemia (CML). These designations predict the clinical course and guide treatment. This review focuses exclusively on ALL.

An estimated $~ 6000$ total new cases of pediatric and adult ALL occur in the U.S. annually, accounting for 1500 deaths/year with most ALL deaths (about 80\%) occurring in adults [1]. In childhood, ALL is arguably the most important cancer. ALL is the most common pediatric malignancy in the U.S., representing $>25 \%$ of all cancer in children $0-14$ years [2,3]. About $85 \%$ of cases are precursor-B (pre-B ALL); the remainder are T-ALL [3,4]. Despite huge strides in pediatric ALL treatment, ALL is still the second most lethal childhood cancer, causing 25\% of deaths [5]. Pediatric ALL is so common, relapsed ALL is actually the fourth most-frequent pediatric cancer diagnosis, with pre-B ALL the main entity [6]. Historically, T-ALL has been considered more aggressive, requires more intense therapy, has inferior outcomes after relapse, and has higher chances of CNS 
involvement and CNS relapse [7], but evolving treatment paradigms have improved pediatric T-ALL outcomes with respect to pre-B ALL [8]. This review focuses on zebrafish ALL models. Traditionally, ALL is categorized as precursor-T (or T-cell (T-ALL)), precursor-B (or pre-B cell (B-ALL)), or mature $B$ cell (Burkitt ALL) based on immunophenotypes of distinct lineage and cell maturational markers. These can be further subdivided according to recurrent karyotypic abnormalities, including specific aneuploidies and translocations $[9,10]$. Although grouped together as ALL, B-ALL and T-ALL exhibit unique biologies that underlie their differing clinical behavior and drug sensitivities. Within each category, multiple genetic sub-categories exist, and these demonstrate even further heterogeneity. Defining the specific features of each genetic subtype of ALL is an active area of investigation that will, hopefully, allow oncologists to tailor therapies matching each ALL's molecular anomalies, a concept oft-termed "precision oncology". Zebrafish can help with this, because their genetic manipulability is unmatched among vertebrate models, and they are already proven to be capable of developing various ALL types that emulate human ALL. Genomic profiling and mutational analyses are refining ALL classification at a rapid pace, identifying new genetic lesions that coexist and cooperate with other known alterations, and finding new ALL subtypes in cases lacking known cytogenetic alterations [10]. Making sense of the discoveries gleaned from human clinical samples at a molecular and mechanistic level is likely one of the principal ways that zebrafish models can enhance progress.

\section{Zebrafish are a Model Befitting Leukemia Modeling}

Over the past few decades, zebrafish (Danio rerio) have emerged as a powerful vertebrate model to recapitulate many diseases, including cancer. There are several attributes that favor $D$. rerio relative to other vertebrates: Low cost of housing, largely due to their small size; high fecundity; external fertilization, ex-utero development, and translucent embryos, all enabling real-time visualization of early embryo- and organo-genesis; ease and speed of genetic manipulation, including simple transgenesis and precise genome-editing approaches to knock-down and overexpress genes by various technologies; and capacity for phenotype-driven genetic and chemical screens to identify genetic interactions, new molecular targets, novel agents, or to re-purpose existing drugs for new indications.

Given their distant evolutionary relationship, it is perhaps surprising how similar zebrafish and humans are genetically. Howe et al. showed that $70 \%$ of human genes have zebrafish orthologues [11]; this aids in correlating gene expression in zebrafish cancers to their human counterparts and with designing transgenic zebrafish that express human (or other mammalian) genes. D. rerio have repeatedly proven to be an excellent model to study blood disorders and hematologic cancers [12-19]. The zebrafish adaptive immune system resembles that of humans [20], and zebrafish thymic architecture is also similar to mammals, containing distinct cortical and medullary regions that compartmentalize maturing $\mathrm{T}$ cells [21]. In addition, the genetic programs governing hematopoiesis, oncogenesis, and tumor suppression are highly conserved between these species [22,23], so much so that transgenic mammalian proteins typically show conserved function in zebrafish. Transgenic fluorescent reporter lines have also been established, enabling live in vivo imaging, cell-lineage tracing, or rapid microscopy screening for cancers. Transplantation protocols, and even immunodeficient zebrafish lines, are now available [24-28], further accelerating D. rerio leukemia studies. Several groups have exploited these and other tools to study ALL in zebrafish. Below, we summarize key studies that have advanced our understanding of human ALL employing experimental strategies in D. rerio.

\section{Zebrafish Acute Lymphoblastic Leukemia Models}

\subsection{T-ALL: Introduction}

T-ALL is an aggressive hematologic malignancy characterized by uncontrolled division of immature T-progenitors (i.e., T-lymphoblasts). T-ALL represents $\sim 25 \%$ of adult and $\sim 15 \%$ of pediatric ALL cases $[3,29]$. Common clinical presentations include hyperleukocytosis and extramedullary involvement of lymph nodes and/or other organs such as the central nervous system, spleen, 
and mediastinal masses, which arise in the thymus [30]. T-ALL and T-cell lymphoblastic lymphoma (T-LBL) are often considered as one disease, differing only by their extent of bone marrow infiltration, and treatments for both are similar, if not identical [31]. Zebrafish models of T-ALL/LBL have advanced dramatically since the groundbreaking work of Langenau et al., who described the first zebrafish T-ALL model in 2003 [32]. Not only was this the first transgenic ALL model in D. rerio, but also the first zebrafish cancer model overall. Now, the number of zebrafish T-ALL models has reached double digits, as summarized below [12-15] (Table 1).

\subsection{Zebrafish T-ALL Models}

\subsubsection{Model 1: T-ALL Induced by Murine $M y c-T g(z r a g 2: E G F P-m M y c)$ Zebrafish}

The first demonstration of stable leukemia-prone transgenic fish used a construct consisting of a zebrafish lymphoblast-specific recombination-activating gene-2 (zrag2) promoter driving a murine $c-M y c(m M y c)$ oncogene. The transgene also contained enhanced green fluorescent protein (EGFP); thus, cancers were fluorescent and could be detected and monitored by simple microscopy [32]. To create this line, fish were microinjected with the transgene as one-cell embryos. All mosaic fish that integrated the transgene developed T-ALL, proving high $(100 \%)$ penetrance of the phenotype. RNA in situ hybridization confirmed $m M y c$ expression, as well as that of T-lineage genes, proving leukemias were T-ALL. Flow cytometric DNA analyses demonstrated T-ALL were clonally aneuploid. T-ALL "immortality" was shown by transplantation into irradiated recipients, with rapid engraftment seen [32]. Leukemias resembled human T-ALL in many ways-they grew rapidly after very short latency that averaged only 52 days post-fertilization (dpf), invaded into multiple lymphoid and non-lymphoid tissues, and exhibited clonal TCR- $\alpha$ gene rearrangements.

Complete penetrance and rapid leukemic onset represented a huge scientific success, but it also created a challenge: T-ALL grew so quickly that many animals died before sexually mature. Thus, maintaining this line was difficult. Ensuing derivative transgenic lines (detailed below) rectified this. Alternatively, in vitro fertilization (IVF) of preserved sperm can maintain zrag2:mMyc fish, or other strategies can be employed: First, since $z r a g 2: m M y c$ is so potent, many labs inject the construct into new embryo clutches to make T-ALL as-needed in whatever genetic background they desire. Second, by freezing T-ALL cells, leukemias can later be injected into new recipients (or even passaged serially through multiple transplant rounds), to propagate individual T-ALL indefinitely.

\section{Key Discoveries}

- Role of MYC in ALL

The success of this model reinforced that MYC was a powerful oncogene, potently driving leukemogenesis across species. MYC's key role in T-ALL and other hematologic malignancies was already established [33-37], and studies of MYC in ALL continue to be published regularly [38,39]. In fact, MYC was also found to drive zebrafish B-ALL, as discussed subsequently.

- $m M y c$ T-ALL Mirrors Most Common Human T-ALL subtype

Characterization by RT-PCR and in situ hybridization showed cancers express both tal1/scl and Imo2 (fish orthologues of known human T-ALL oncogenes TAL1/SCL and LMO2), emulating the most common molecular T-ALL subtype in patients [40,41]. Of note, the zrag2 promoter used in this line has been utilized to create nearly every other transgenic zebrafish ALL model thus far described, attesting to its utility, but also revealing a limitation in the field that investigators should address in future studies. 
- Role of DLST and TCA Metabolism in T-ALL

Others have used " $m M y c$ fish" to find T-ALL genetic modifiers. Anderson et al. performed a candidate genetic screen that revealed a role for dihydrolipoamide S-succinyltransferase (DLST) and tricarboxylic acid cycle (TCA) metabolism in T-ALL [42]. DLST is part of a TCA cycle enzymatic complex that dehydrogenates $\alpha$-ketoglutarate $(\alpha-\mathrm{KG})$ into succinyl-CoA, and heterozygous inactivation of dlst significantly delayed $m M y c$-driven zebrafish T-ALL. Findings were corroborated in human T-ALL cell lines, where DLST RNAi knockdown led to impaired viability and apoptosis due to TCA cycle disruption and $\alpha-K G$ accumulation. Addition of the downstream intermediate succinate rescued DLST inactivation-induced viability defects. Overall, this study proved metabolic dependence of T-lymphoblasts on the TCA cycle, providing opportunities for targeted therapy [42].

- Creating a Transplantable Zebrafish T-ALL Cell Line with zrag2:EGFP-mMyc CG2 Fish

Mizgirev et al. created a zebrafish T-ALL line, ZL1, to screen anti-leukemia agents. Specifically, they built a T-ALL line that could be transplanted into syngeneic hosts, facilitating production of many zebrafish bearing synchronously growing T-ALL [43]. They first created a novel CG2 (Clonal Golden 2) line comprised of genetically near-identical fish $[44,45]$. They then injected zrag2:EGFP-mMyc into CG2 embryos to create the ZL1 T-ALL line, and subsequently propagated it through $>20$ transplant passages in adult CG2 fish. Next, they tested the human T-ALL chemotherapeutics cyclophosphamide (CY), vincristine (VCR), and prednisolone (PRE) for efficacy in zebrafish larvae harboring ZL1, using increased lifespan as their outcome variable. They demonstrated dose- and time-dependent effects for $\mathrm{CY}$ and VCR, but as in human T-ALL, monotherapy with either did not cure disease. In their study, PRE was not effective at doses of 1-50 mg/L for treatments of $24-72 \mathrm{~h}$ due to toxicity occurring exclusively in ZL1-bearing larvae. This model, or others like it, could provide cost-effective platforms for large-scale anti-cancer compound screens [43].

\subsubsection{Model 2: T-ALL in Conditional $m M y c$ Models}

Model 2a: rag2:loxP-dsRED2-loxP-EGFP-mMyc [aka, Tg(rag2:LDL-EMyc)] Zebrafish

The $m M y c$ line was modified, using conditional Cre-Lox technology to overcome the need for IVF [40]. Here, the EGFP-mMyc construct was preceded by a loxP-DsRed2-loxP cassette. In theory, without Cre, $m M y c$ would not be expressed and $d s R E D 2$ (a red fluorophore) would label immature thymocytes. To express EGFP-mMyc, Cre recombinase could be injected into one-cell embryos carrying the transgene, causing loxP-mediated excision of $d s R E D 2$ and expression of EGFP-mMyc. Presumably due to less-than-100\% Cre efficiency, fish developed T-ALL with longer mean latency of $151 \mathrm{dpf}$ (vs. $52 \mathrm{dpf}$ in the original line), and T-ALL remained morphologically similar to the original $m M y c$ line. However, suboptimal recombination and mosaic EGFP-mMyc activation did pose challenges. Only $\sim 7 \%$ of Cre-injected fish developed T-ALL, and most expressed both dsRED2 and GFP, suggesting leukemic cells had only partial Cre recombination of a transgenic locus harboring multiple rag2:loxP-dsRED2-loxP-EGFP-mMyc copies [40]. Mosaicism was further indicated by a single fish with one T-ALL clone expressing both dsRED2 and GFP in one thymus, and a second T-ALL expressing only GFP in the other thymus [40].

Model 2b: Double-Transgenic [Tg(hsp70:Cre;rag2:LDL-EMyc)] Zebrafish

A variant of the conditional model above improved its low penetrance. Here, Cre injection was replaced by a heat shock-inducible Cre transgene, hsp70:Cre [46]. Double-transgenic (hsp70:Cre;rag2:LDL-EMyc) $3 \mathrm{dpf}$ embryos were heat shocked to induce Cre. This markedly improved T-ALL penetrance, $(\sim 80 \%)$, with mean latency of $120 \mathrm{dpf}$, overcoming both limitations of prior models. These fish were easier to maintain, and amenable to studies like forward-genetic screens. A (potential) drawback of this line was that without heat shock, T-ALL still occurred in $13 \%$ of animals, although 'leakiness' was lessened by raising fish at $24{ }^{\circ} \mathrm{C}$ and/or PCR-screening for fish with no or 
little recombination. Even so, $\sim 90 \%$ of non-heat shocked fish remained cancer-free by $201 \mathrm{dpf}$, so these fish were simpler to maintain [46].

- Key Discoveries

Using this Cre-inducible line, the original rag2:mMyc line, and a third transgenic with human MYC (detailed subsequently), Huiting et al. investigated ubiquitin fusion degradation 1 (UFD1) in $m M y c$-driven zebrafish T-ALL [47]. They found MYC up-regulated UFD1 in T-ALL, and allelic loss of zebrafish $u f d 1$ induced T-ALL apoptosis, impairing cancer progression. Akin to the previously cited DLST study, this identified UFD1 as a genetic modifier in MYC-driven T-ALL, with potential utility for developing targeted therapy [47].

\section{Model 2c: Triple-Transgenic [Tg(hsp70:Cre;rag2:LDL-EMyc;rag2:EGFP-bcl2)] Zebrafish}

Double-transgenic heat shock-inducible $m M y c$ fish were further modified to analyze the role of zebrafish $b c l 2$, a BH3-family anti-apoptotic gene, with respect to autophagy and thymic T-LBL progression to disseminated T-ALL. This is one of the only studies to probe differences between these two closely related cancers often viewed as one disease [48]. Triple-transgenic fish with hsp70:Cre, rag2-LDL-EGFP- $m M y c$, and rag2:EGFP-bcl2 were built, creating T-lymphoblast cancers with constitutive $b c l 2$ overexpression. They exhibited earlier onset and higher penetrance of T-LBL than double-transgenic fish lacking rag2:bcl2, suggesting $b c l 2$ accelerated MYC-induced T-cell cancer.

- Key Discoveries

Remarkably and likely unexpectedly, while accelerating T-LBL, bcl2 overexpression profoundly inhibited T-LBL progression to T-ALL. Cells overexpressing $b c l 2$ failed to invade the vasculature and showed increased autophagy. This prompted the conclusion that autophagy was due to the inability of T-LBL cells to disseminate-they proliferated until they exhausted local nutrient supply, causing metabolic stress and autophagy. Conversely, lower Bcl2 levels allowed alternative cell survival programs through pathways promoting dissemination to avoid autophagy. This potentially unravels a biological basis to explain why some patients have localized T-LBL, while others exhibit rapidly disseminating T-ALL [48]. In addition, Feng et al. showed elevated S1P1 signaling and increases in its downstream target ICAM1 promoted homotypic cell adhesion through ICAM1-LFA1 binding. Together, this impeded intravasation and thymic egress, preventing hematologic dissemination and promoting autophagy. Their findings were confirmed in human biopsies, where autophagy markers and increased BCL2 $\alpha$, S1P1, and ICAM1 were seen in T-LBL compared to T-ALL. S1P1 inhibition in T-LBL cells decreased homotypic adhesion in vitro and increased tumor intravasation in vivo. An important potentially translatable finding from this study was that AKT promoted T-LBL progression to T-ALL, suggesting PI3K-AKT inhibitors might prevent T-LBL dissemination [48].

\subsubsection{Model 3: Co-Injection Strategies Pairing zrag2:EGFP-mMyc with Other Transgenes}

Langenau et al. reported another approach to modify T-ALL initiation, co-injecting multiple transgenes to overcome some limitations in the aforementioned models [49]. Their method aimed to rapidly assess synergism or antagonism between combinations of genes, by injecting multiple transgenes simultaneously. To assess whether different transgene constructs co-integrated, rag2:mMyc and rag2:dsRED2 were co-injected into stably transgenic rag2:GFP fish. All T-ALL that developed were both GFP+ and dsRED2+, indicating transgenes co-integrated and were co-expressed. With the knowledge that multiple transgenic constructs behaved as one in vivo, this study provided key proof-of-concept that co-injection strategies could rapidly interrogate (potentially) collaborating genes and pathways [49]. 
Key Discoveries

Co-injection is powerful because hundreds of embryos can be injected with multiple transgene combinations; consequently, many investigators now employ this. Examples utilizing this approach include the following:

- Transplantation into Syngeneic CG1-Strain Zebrafish

Smith et al. co-injected one of four fluorescent transgenes (rag2:GFP, rag2:dsRED, rag2:zsYellow, or rag2:Amcyan) plus rag2:mMyc to create different colored T-ALL in the syngeneic CG1 background [44,45]. They then transplanted very low numbers of T-ALL cells into CG1 recipients, which allowed transplantation into hosts without irradiation or immunosuppression [44]. T-ALL successfully engrafted from very few cells, accurately quantifying leukemia-initiating cells (LIC) and showing that $0.1-1.4 \%$ of $m M y c$ primary T-ALL cells have LIC activity. Using large-scale single-cell transplantation, they further proved T-ALL can arise from single transplanted cells, and that LIC frequencies vary considerably between individual T-ALL. Remarkably, they transplanted $>1400$ fish in this study, showing that zebrafish are amenable to large-scale transplant projects that would be financially and practically infeasible in mammalian models [44].

- Modeling Treatment Resistance and Relapse

Similarly, co-injecting $m \mathrm{Myc}$ together with any of several fluorophores, Blackburn et al. investigated how clonal evolution and heterogeneity drive cancer progression, studying differences between T-ALL clones [50]. Functional variation in individual clones revealed changing growth rates and LIC frequencies over time. Some T-ALL cells spontaneously acquired mTORC1 activation, which stabilized MYC to shorten T-ALL latency and increase LIC. This also fostered dexamethasone resistance, despite no prior exposure. AKT inhibition reversed this. They concluded T-ALL cells stochastically acquire mutations that cause treatment resistance even before drug exposure, in effect driving relapse before therapy even begins. Further, in their model, dexamethasone and AKT inhibition showed anti-LIC activity [50].

\subsubsection{Model 4: Inducible T-ALL in rag2:hMYC-ER Transgenic Zebrafish}

MYC is an established oncogenic transcription factor that is highly expressed by many T-ALL, and NOTCH1 activation, also common in T-ALL, fosters MYC expression [34-36]. The PTEN-PI3K-AKT axis is also frequently deranged in T-ALL [51,52], and cases with PTEN and/or PI3K-AKT alterations often overexpress MYC too [51]. To explore these interactions, Gutierrez et al. built a conditional zebrafish model with transgenic human MYC ( $M M Y C$ ). They fused $h M Y C$ to a modified estrogen receptor $(E R)$ that binds 4-hydroxytamoxifen $(4 \mathrm{HT})$, but not endogenous estrogens. Once again, the zebrafish rag2 promoter controlled transgene expression. 4HT treatment causes nuclear translocation of the $h M Y C-E R$ fusion, thereby post-translationally activating MYC in an inducible, and reversible, manner. Exposing rag2:hMYC-ER larvae to 4 HT beginning at $5 \mathrm{dpf}$ caused $100 \%$ T-ALL penetrance by five weeks of age, but many cancers regressed upon $4 \mathrm{HT}$ withdrawal, suggesting some 'leukemias' were not stably transformed, but rather lymphoproliferations that relied upon very high MYC activity. Subsequent studies revealed even without $4 \mathrm{HT}$ treatment, T-ALL occurs in most animals by nine months $[53,54]$.

Key Discoveries

- MYC, PTEN, and PI3K-AKT Interactions in T-ALL

This study demonstrated loss-of-function of endogenous pten, or a constitutively active myristoylated murine Akt2 ( $m y r-m A k t 2$ ) transgene, both render T-ALL less reliant upon MYC, promoting T-ALL persistence despite $4 \mathrm{HT}$ withdrawal. This suggests MYC-dependency is partly mediated by Pten, which inhibits the Pi3k-Akt pathway. Additional studies indicated Akt promoted T-cell migration, 
suppressed autophagy, and inhibited apoptosis [55]. Collectively, their findings implied PI3K-AKT inhibitors may be useful—especially if combined with MYC inhibitors—for T-ALL treatment. Reynolds et al. further explored these ideas, investigating the pro-apoptotic protein BIM with respect to MYC. Using rag2:hMYC-ER fish, they showed MYC down-regulation induced BIM, favoring apoptosis, but this was blunted by constitutively active myr-mAkt2 [56]. They extended this concept to human T-ALL studies, concluding that BIM repression is a key event downstream of MYC and PI3K-AKT in treatment-resistant T-ALL.

- Drug Screening in rag2:hMYC-ER Zebrafish

$h M Y C$ fish were also used in a drug screen seeking agents cytotoxic to MYC-overexpressing thymocytes [57]. Embryos carrying a rag2:dsRed2 marker, either with or without rag2:hMYC-ER, were incubated with $4 \mathrm{HT}$ to activate MYC-ER, plus 4880 agents from four compound libraries. After four days (3-7 dpf), thymic fluorescence was assessed. Ultimately, this work revealed Perphenazine (PPZ), an FDA-approved antipsychotic, could induce apoptosis of fish, mouse, and human T-ALL. They identified protein phosphatase 2A (PP2A) as a PPZ target that was activated-not inhibited-by PPZ. Treatment with PPZ suppressed human T-ALL growth, dephosphorylating PP2A targets in vitro and in vivo. Overall, this suggested therapeutic potential for PP2A as a target in T-ALL [57].

- Discovery of T-ALL in rag2:myr-mAkt2 Zebrafish

The original $h M Y C$ report also made a second, somewhat underappreciated finding. In creating rag2:myr-mAkt2 transgenic fish, Gutierrez et al. also showed mAkt2 by itself could induce T-ALL, albeit less potently than $h M Y C$ [55]. In $m A k t 2$-transgenic controls, $17 \%$ of fish developed T-ALL by 20 weeks, demonstrating Akt alone could induce T-ALL. To our knowledge, this model has not been explored further, but could likely also advance our understanding of T-ALL molecular events [55].

\subsubsection{Model 5: Zebrafish NOTCH T-ALL Models}

Model 5a: Transgenic Human NOTCH1-Tg(rag2:hICN1-EGFP) Zebrafish

NOTCH1-activating mutations occur in $>50 \%$ of human T-ALL cases, across multiple molecular subtypes [58]. Hence, it was natural that one of the earliest zebrafish T-ALL models focused on this gene. Specifically, Chen et al. created transgenic zebrafish expressing "human intracellular NOTCH1" (hICN1), a constitutively active truncated NOTCH1 protein [59]. As in some $m M y c$ models, hICN1 was fused to EGFP, and the zebrafish rag2 promoter was once again used. T-ALL developed in $>40 \%$ of mosaic animals by five months, sufficient latency to maintain the line. ALL were confirmed to be T-lineage, oligoclonal, and transplantable. As in $m M y c$ and $h M Y C$ fish, T-ALL were aggressive, invading throughout animals. By RT-PCR, the authors showed hICN1 activated D. rerio homologues of known human NOTCH1 targets such as her6 and her9. Unfortunately, stable rag2:ICN1-EGFP transgenic fish showed longer latency ( 11 months; penetrance remained $\sim 40 \%$ ), and likely due to this, this model has not been widely studied.

- Key Discoveries

When hICN1-transgenic fish were crossed to animals overexpressing anti-apoptotic zebrafish $b c l 2$, T-ALL showed accelerated onset and higher incidence, indicating synergy between NOTCH1 and BCL2. Progression from T-LBL to T-ALL was not reported upon, but in view of later findings from double-transgenic $m M y c+b c l 2$ fish [48], such investigations are perhaps warranted. Notably, in multiple studies, endogenous myca and $m y c b$ are not up-regulated in ICN1-induced T-ALL [59,60], although NOTCH1 induces MYC in human T-ALL [34,36,61]. He et al. proposed that D. rerio c-MYC homologues may lack upstream NOTCH1-driven enhancers, which are described in mammals, potentially explaining this difference $[13,62]$. This apparent distinction allows investigators to examine NOTCH1- and MYC-mediated actions separately in D. rerio T-ALL, which is not possible in mammals, but also highlights potentially important mechanistic differences between zebrafish and human T-ALL. 
Model 5b: Transgenic Zebrafish Notch1-Tg (rag2:znotch1a ICD)

Blackburn et al. created fish with either rag2:hICN1 or rag2:znotch1a ${ }^{I C D}$ (notch1a is one of two zebrafish NOTCH1 homologues; "ICD" refers to a truncation analogous to human ICN1). Both were paired with rag2: $m M y c$ in double-transgenic animals [60]. As noted, zebrafish are well-suited to study independent roles of NOTCH1 and MYC, since unlike in mammals, hICN1 does not up-regulate endogenous zebrafish $m y c$ homologues. Moreover, to date, notch1a and notch $1 b$ mutations have not been reported in zebrafish MYC-driven T-ALL, despite the high prevalence of NOCTH1 mutations in human T-ALL. In this report, $h I C N 1 / z n o t c h 1 a^{I C D}$ augmented $m M y c$ to accelerate cancer onset, but did not alter T-ALL proliferation or apoptosis. RNA expression studies also revealed a shared signature in fish, mouse, and human T-ALL, suggesting conservation of key molecular circuitry for a 'Notch profile.' They hypothesized that NOTCH1 mutations are likely an initiating event in human T-ALL that expands pre-malignant thymocytes, with only a subset of cells acquiring additional mutations to become fully transformed.

\section{- Key Discoveries}

NOTCH1 activation alone is insufficient to induce T-ALL, requiring additional oncogene-activating and/or tumor suppressor-inactivating mutations. At least in zebrafish, NOTCH and MYC do not collaborate to enhance LIC, as T-ALL with mMyc and Notch1a ${ }^{\mathrm{ICD}}$ or those with only mMyc show similar LIC frequencies [60].

\subsubsection{Models 6-8: Non-Transgenic T-ALL Models}

Frazer et al. reported a chemical mutagenesis forward-genetic screen for T-ALL-prone zebrafish [63]. They exposed lck:EGFP transgenic fish, which express GFP highly in T-lineage cells due to their ardent lck expression [64], to N-ethyl-N-nitrourea (ENU), an alkylator that randomly induces genomic mutations. ENU-exposed males then sired large clutches of fish that were screened for GFP+ tumors. To verify heritable transmission, progeny of fish developing T-ALL were likewise screened for GFP+ cancers. Ultimately, they isolated three cancer-predisposed D. rerio lines, dubbed $h l k$, srk, and $o t g$, and demonstrated malignancies were T-ALL. These lines exhibited different T-ALL penetrance in homozygous and heterozygous mutants, with peak incidence at 5-9 months, and unique expression signatures in non-malignant T cells and T-ALL of each mutant. Morphologic features of T-ALL and patterns of disease spread resembled transgenic MYC and NOTCH zebrafish, as well as in human T-ALL. TCR $\beta$ analyses confirmed T-ALL clonality, and allogeneic transplants verified transformed T cells were immortal. Unfortunately, due to incomplete penetrance in both homozygous vs. heterozygous mutants and the highly polymorphic nature of the zebrafish genome, the germline mutations that $h l k$, srk, and otg represent are unidentified.

\section{Key Discoveries}

Overall, this report was unique in proving that endogenous mutations-as opposed to transgenes-could also drive zebrafish T-ALL. It further established that forward-genetic approaches could successfully identify complex phenotypes like cancer-predisposition that manifest later in development (i.e., not in embryos/larvae). These models were subsequently used to explore somatically acquired genetic changes occurring in T-ALL, specifically those contributing to relapse. Rudner et al. serially allo-transplanted $h l k$, srk, and otg T-ALL, examining primary and passaged cancers via array comparative genomic hybridization (aCGH). [65] Copy number aberrations were then compared to those in a cohort of 75 human T-ALL also analyzed by aCGH. This revealed several amplified and deleted genes shared by T-ALL of both species, including loci linked to poor clinical outcome. 


\subsubsection{Model 9: T-ALL Induced by ARID5B-Tg(rag2:hARID5B) Zebrafish}

Leong et al. identified roles for AT-rich interactive domain 5B (ARID5B) in T-ALL expression patterns, cell growth, and survival. [66] Specifically, they showed ARID5B reinforced an oncogenic signature that positively regulated both MYC and a TAL1/SCL. ARID5B also regulated other members of the TAL1 transcriptional complex besides TAL1, and co-occupied TAL1 targets with TAL1, reinforcing a genetic program that drives T-ALL. Reciprocally, they showed ARID5B is a TAL1 transcriptional target. Employing a familiar strategy, they built rag2:hARID5B + rag2:mCherry double-transgenic zebrafish to analyze ARID5B overexpression, and this stable transgenic line displayed several interesting phenotypes: (1) Thymic involution, which normally begins at $\sim 3$ months, was delayed (and perhaps prevented). (2) Non-malignant thymocytes showed marked $\gamma$-irradiation resistance. (3) A small number of fish $(2 / 38 ; \sim 5 \%)$ developed T-LBL/ALL by six months, with cancers overexpressing either endogenous $m y c a$ or $m y c b$, and other genes consistent with an immature thymocyte developmental arrest.

\section{Key Discoveries}

This line had low T-ALL penetrance, which may limit its future applications. Likewise, characterization was limited to analysis of only two T-ALL. Nonetheless, this study provides an example of how zebrafish can rapidly interrogate candidate genes in vivo. Here, the preponderance of work was performed in Jurkat and other human T-ALL cell lines, implicating ARID5B as a possible T-ALL oncogene. To functionally test this, the authors built a straightforward model, and using simple fluorescent microscopy assays (monitoring thymic size with aging, after irradiation, or to identify tumors) were able to demonstrate that ARID5B can in fact induce T-ALL.

\subsubsection{Model 10: T-ALL Induced by jdp2-Tg(rag2:zjdp2) Zebrafish}

Mansour et al. studied JDP2, a transcription factor implicated by unbiased genome-wide T-ALL studies in mice, using zebrafish [67]. In humans, they found JDP2 expression was normally restricted in developing thymocytes, but high in many T-ALL, particularly the early thymocyte progenitor subtype, ETP-ALL. T-ALL cases with higher JDP2 expression had inferior outcomes, especially ETP-ALL patients. JDP2 depletion caused apoptosis of human T-ALL cell lines, and they linked this transcriptional regulation of anti-apoptotic MCL1 by JDP2. They also performed several zebrafish studies: (1) Fish injected with rag2:mMyc + rag2:zjdp2 showed accelerated T-ALL onset compared to fish with rag2:mMyc alone. (2) Stably transgenic rag2:zjdp2 fish exhibited thymic hyperplasia, delayed involution, and after 9-12 month latency, 50\% incidence of T-ALL that could engraft into immunodeficient larvae and adult fish. (3) Supporting their prior results, rag2:zjdp2 thymocytes had elevated mcl1 RNA, and presumably due to this, were resistant to glucocorticoids. Overall, this study convincingly demonstrated oncogenic roles for JDP2 in T-ALL, as well as a link to MCL1 that may explain why JDP2+ T-ALL patients do poorly.

\section{Key Discoveries}

This report provided evidence that JDP2 is not only an oncogenic driver (proven by rag2:zjdp2 fish developing T-ALL), but also a possible cause of treatment failure (revealed by thymocyte glucocorticoid resistance). Comparing steroid sensitivity of $m M y c$ - vs. zjdp2-driven T-ALL could have addressed this even more definitively. Even so, models like rag2:zjdp2 and rag2: $m M y c+r a g 2: z b c l 2$ fish provide powerful in vivo templates to discover and pre-clinically test novel agents that circumvent steroid resistance, an important problem not just in T-ALL, but lymphocyte malignancies in general, including B-ALL. 


\subsection{B-ALL: Introduction}

B-ALL is the most common type of ALL in both children and adults, representing $85 \%$ of pediatric ALL and $75 \%$ of adult cases $[68,69]$. Like T-ALL, which are often classified by oncogenic transcription factors [61,70], B-ALL can be separated into molecular subgroups depending on their genetic aberrations [71]. Many subgroups are defined by translocations that create oncogenic fusion proteins that then transform B cell progenitors, such as the "Philadelphia chromosome" (BCR-ABL1), ETV6-RUNX1, and TCF3-PBX1 [68]. Other B-ALL subtypes are characterized by global genetic features, such as hyperdiploidy ( $>50$ chromosomes) or hypodiploidy $(<44$ chromosomes) [68], or specific transcriptional profiles: PAX5-driven subtypes, DUX4-rearranged, BCR-ABL1-like, or ETV6-RUNX1-like [71-73]. Subtype frequencies differ between children and adults, but essentially all types occur in both patient populations [71]. Translocations or specific mutations are likely initiating events in B-ALL, but additional (epi) genetic events are probably required for B-ALL to develop [73]. Several murine models develop B-ALL when engineered with human B-ALL driver mutations, such as $M L L$ fusions [74-76]. B-ALL incidence increases with the addition of secondary genetic events, like $B c l 2$ overexpression or Kras activation [75]. Few reports of zebrafish B-ALL exist, although differences between $D$. rerio and human B cells are comparably similar to those between T cells of these species [77]. The many successful zebrafish T-ALL models suggest $D$. rerio can likely emulate several human B-ALL subtypes, but currently, zebrafish B-ALL models lag behind $[13,15]$. Here, we will review the three zebrafish B-ALL models reported to date (Table 1), but it is likely many others will soon follow. 
Table 1. Summary of zebrafish acute lymphoblastic leukemia (ALL) models.

\begin{tabular}{|c|c|c|c|c|c|c|c|c|}
\hline \multirow{2}{*}{\multicolumn{2}{|c|}{ T-ALL Models }} & \multicolumn{3}{|c|}{ Transgenes (Promoter:Oncogene) } & \multirow{2}{*}{ Incidence (\%) } & \multirow{2}{*}{$\begin{array}{c}\text { Mean } \\
\text { Latency } \\
\text { (dpf) }\end{array}$} & \multirow{2}{*}{ Key Features } & \multirow{2}{*}{ Other Remarks } \\
\hline & & Promoter & Oncogene(s) & Full Construct & & & & \\
\hline Model 1 & Murine $M y c(m M y c)$ & rag2 & $m M y c$ & rag2:EGFP-mMyc & 100 & 52 & $\begin{array}{l}\text { T-ALL mirrored most } \\
\text { common TAL1 human } \\
\text { T-ALL subtype; used as a } \\
\text { foundation for several } \\
\text { ensuing T-ALL studies }\end{array}$ & $\begin{array}{l}\text { First transgenic zebrafish ALL } \\
\text { and cancer model; complete } \\
\text { penetrance and short latency } \\
\text { created challenges [32] }\end{array}$ \\
\hline Model 2a & $\begin{array}{l}\text { Cre-Lox conditional } \\
m M y c\end{array}$ & rag2 & $m M y c$ & $\begin{array}{c}\text { rag2:loxP-dsRED2-loxP- } \\
\text { EGFP-mMyc }\end{array}$ & 7 & 151 & $\begin{array}{l}\text { Used Cre recombinase } \\
\text { injection to induce } \\
E G F P-m M y c \text { expression }\end{array}$ & Low penetrance [40] \\
\hline Model 2b & $\begin{array}{l}\text { Heat shock inducible } \\
\text { Cre with } m M y c\end{array}$ & rag2 & $m M y c$ & hsp70:Cre;rag2:LDL-EGFP-mMyc & 80 & 120 & $\begin{array}{l}\text { Used heat shock-inducible } \\
\text { Cre transgene to markedly } \\
\text { improve T-ALL penetrance }\end{array}$ & $\begin{array}{l}\text { Easier to maintain and amenable } \\
\text { to forward-genetic screens [46] }\end{array}$ \\
\hline Model 2c & Above line with $b c l 2$ & rag2 & $m M Y C / b c l 2$ & $\begin{array}{c}\text { hsp70:Cre;rag2:LDL- } \\
\text { EGFP-mMyc;rag2:EGFP-bcl2 }\end{array}$ & $>80$ & $<120$ & $\begin{array}{l}\text { T-LBL favored over T-ALL } \\
\text { due to constitutive } b c l 2 \\
\text { expression }\end{array}$ & $\begin{array}{l}\text { Used to study differences } \\
\text { between T-LBL and T-ALL [48] }\end{array}$ \\
\hline Model 3 & $\begin{array}{l}\text { Co-injection of } \\
\text { multiple transgenes }\end{array}$ & rag2 & $m M y c$ & $\begin{array}{l}\text { rag2: } m M y \text { c and rag2:dsRED2 } \\
\text { co-injected into stably } \\
\text { transgenic rag2:GFP fish }\end{array}$ & N/A & N/A & $\begin{array}{l}\text { Proved use of co-injection, } \\
\text { allowing hundreds of } \\
\text { embryos to be injected with } \\
\text { multiple transgene } \\
\text { combinations }\end{array}$ & $\begin{array}{c}\text { Used to color-code T-ALL in the } \\
\text { syngeneic CG1 background for } \\
\text { LIC and cancer heterogeneity } \\
\text { studies [49] }\end{array}$ \\
\hline \multirow[t]{2}{*}{ Model 4} & Human $M Y C(h M Y C)$ & rag2 & $h M Y C$ & rag2:hMYC-ER & $\begin{array}{l}100 \text { (4HT } \\
\text { treated fish) }\end{array}$ & 37 & $\begin{array}{l}\text { 4HT-inducible } h M Y C \\
\text { expressing T-ALL used to } \\
\text { study MYC and PI3K-AKT } \\
\text { interaction. }\end{array}$ & $\begin{array}{l}\text { Showed BIM repression is a key } \\
\text { event downstream of MYC and } \\
\text { PI3K-AKT in resistant T-ALL; } \\
\text { also used to show therapeutic } \\
\text { potential for PP2A in T-ALL [55] }\end{array}$ \\
\hline & $\begin{array}{l}\text { Myristoylated murine } \\
\text { Akt2 (myr-mAkt2) }\end{array}$ & rag2 & $m y r-m A k t 2$ & rag2:myr-mAkt2 & 17 & 140 & $\begin{array}{l}\text { Showed } m y r-m A k t 2 \text { could } \\
\text { induce T-ALL in isolation }\end{array}$ & $\begin{array}{c}\text { Low incidence and has not been } \\
\text { extensively studied [55] }\end{array}$ \\
\hline Model 5a & $\begin{array}{l}\text { Human NOTCH1 } \\
\text { (hICN1) }\end{array}$ & rag2 & hICN1 & rag2:hICN1-EGFP & 40 & 330 & $\begin{array}{l}\text { NOTCH1 induced T-ALL } \\
\text { without up-regulating } \\
\text { endogenous myca and mycb }\end{array}$ & $\begin{array}{l}\text { Allows NOTCH1 and MYC to be } \\
\text { studied separately, not possible } \\
\text { in mammals [59] }\end{array}$ \\
\hline Model 5b & $\begin{array}{l}\text { Zebrafish notch1a } \\
\quad(\text { znotch } 1 a)\end{array}$ & rag2 & znotch $1 a^{I C D}$ & rag2:znotch1a $a^{I C D}$ & 100 & $<52$ & $\begin{array}{c}\text { hICN1/znotch1a }^{\text {ICD }} \\
\text { accelerated T-ALL, but did } \\
\text { not alter T-ALL } \\
\text { proliferation or apoptosis }\end{array}$ & $\begin{array}{l}\text { Showed NOTCH1 activation } \\
\text { alone was insufficient to induce } \\
\text { T-ALL [60] }\end{array}$ \\
\hline Model 6-8 & $\begin{array}{l}\text { Germline mutants: } \\
h l k, \text { srk, and otg }\end{array}$ & $\mathrm{N} / \mathrm{A}$ & $\mathrm{N} / \mathrm{A}$ & N/A & $\begin{array}{c}40-50 \text { in } \\
\text { homozygotes }\end{array}$ & $150-270$ & $\begin{array}{c}\text { Showed endogenous } \\
\text { mutations could also drive } \\
\text { zebrafish T-ALL }\end{array}$ & $\begin{array}{l}\text { Mutant genes were never } \\
\text { identified [63] }\end{array}$ \\
\hline
\end{tabular}


Table 1. Cont.

\begin{tabular}{|c|c|c|c|c|c|c|c|c|}
\hline \multirow{2}{*}{\multicolumn{2}{|c|}{ T-ALL Models }} & \multicolumn{3}{|c|}{ Transgenes (Promoter:Oncogene) } & \multirow{3}{*}{$\begin{array}{c}\text { Incidence (\%) } \\
5\end{array}$} & \multirow{3}{*}{$\begin{array}{c}\begin{array}{c}\text { Mean } \\
\text { Latency } \\
\text { (dpf) }\end{array} \\
180\end{array}$} & \multirow{3}{*}{$\begin{array}{c}\text { Key Features } \\
\begin{array}{c}\text { Proved role of } A R I D 5 B \text { in } \\
\text { T-ALL }\end{array}\end{array}$} & \multirow{3}{*}{$\begin{array}{c}\text { Other Remarks } \\
\begin{array}{c}\text { Fish also showed delayed thymi } \\
\text { involution, and thymocytes } \\
\text { showed radiation resistance. [66 }\end{array}\end{array}$} \\
\hline & & \multirow{2}{*}{$\begin{array}{c}\text { Promoter } \\
\text { rag2 }\end{array}$} & \multirow{2}{*}{$\begin{array}{c}\text { Oncogene(s) } \\
\text { hARID5B }\end{array}$} & \multirow{2}{*}{$\begin{array}{l}\text { Full Construct } \\
\text { rag2:hARID5B }\end{array}$} & & & & \\
\hline Model 9 & Human ARID5B & & & & & & & \\
\hline Model 10 & Zebrafish $j d p 2$ & rag 2 & $z j d p 2$ & $\operatorname{rag} 2: z j d p 2$ & 50 & $270-360$ & $\begin{array}{l}\text { Proved role of } j d p 2 \text { in } \\
\text { T-ALL and linked } m c l 1 \text { to } \\
\text { drug resistance }\end{array}$ & $\begin{array}{c}\text { Fish also showed thymic } \\
\text { hyperplasia and delayed thymic } \\
\text { involution [67] }\end{array}$ \\
\hline \multirow{2}{*}{\multicolumn{2}{|c|}{ B-ALL Models }} & \multicolumn{3}{|c|}{ Transgenes (promoter:oncogene) } & \multirow{2}{*}{ Incidence } & \multirow{2}{*}{$\begin{array}{c}\text { Mean } \\
\text { Latency } \\
(\mathrm{dpf})\end{array}$} & \multirow{2}{*}{ Key Features } & \multirow{2}{*}{ Other Remarks } \\
\hline & & Promoter & Oncogene(s) & Full Construct & & & & \\
\hline Model 1 & $\begin{array}{l}\text { Human TEL-AML1 } \\
\text { (ETV6-RUNX1) }\end{array}$ & $\begin{array}{c}\text { Xenopus ef1a } \\
\text { (Xef1a)/zebrafish } \\
\text { beta-actin (zba) }\end{array}$ & $T E L-A M L 1$ & $\begin{array}{l}\text { Xef1a:TEL-AML1 and } \\
\quad z b a: T E L-A M L 1\end{array}$ & 3 & 360 & $\begin{array}{l}\text { Long latency and low } \\
\text { incidence recapitulate } \\
\text { human TEL-AML1 B-ALL }\end{array}$ & $\begin{array}{l}\text { Models the most prevalent type } \\
\text { of pediatric ALL [78] }\end{array}$ \\
\hline Model 2 & Murine $M y c(m M y c)$ & rag 2 & $m M y c$ & rag2:EGFP-mMyc & Not reported & $\begin{array}{c}\text { Not } \\
\text { reported }\end{array}$ & $\begin{array}{l}\text { Develops ighm+ B-ALL (in } \\
\text { addition to T-ALL) }\end{array}$ & $\begin{array}{l}\text { Unexpectedly unique expression } \\
\text { signature from } h M Y C \text { B-ALL [79] }\end{array}$ \\
\hline Model 3 & Human $M Y C$ ( $h M Y C)$ & rag 2 & $h M Y C$ & rag2:hMYC-ER & Not reported & $\begin{array}{l}\text { Not } \\
\text { reported }\end{array}$ & $\begin{array}{l}\text { Develops ighz+ B-ALL (in } \\
\text { addition to T-ALL) }\end{array}$ & $\begin{array}{c}\text { Only large zebrafish B-ALL } \\
\text { study; unexpectedly unique } \\
\text { expression signature from } m M y c \\
\text { B-ALL [54] }\end{array}$ \\
\hline
\end{tabular}




\subsection{B-ALL Zebrafish Models}

\subsubsection{Model 1: Transgenic hTEL-AML1 Zebrafish}

The $\mathrm{t}(12 ; 21)(\mathrm{p} 13 ; \mathrm{q} 22)$ translocation encodes a TEL-AML1 (ETV6-RUNX1) fusion protein occurring in the most common pediatric B-ALL subtype, representing $\sim 25 \%$ of cases [72,73]. To recapitulate this, Sabaawy et al. created a transgenic $h T E L-A M L 1$ zebrafish line [78]. In this transgenic line, the human fusion TEL-AML1 was expressed under the control of three different promoters: Xenopus ef1a (Xef1a), zebrafish beta-actin ( $z b a$ ), and zebrafish rag2. Xef1a and zba were used to test global expression of TEL-AML1 and the rag2 promoter was used to direct lymphoblast-specific expression. Somewhat surprisingly, global TEL-AML1, but not lymphoblast-specific expression, induced B-ALL in $~ 3 \%$ of fish after a $\sim 12$ month latency. Sabaawy et al. also reported $\sim 6 \%$ of ubiquitously expressing TEL-AML1 fish developed fatal lymphoid hyperplasia as early as $28 \mathrm{dpf}$ with manual differential blood cell counts confirming increased numbers of immature blast-like cells $(\sim 10 \%-15 \%$, just below the level required to diagnose ALL in patients). A unique feature of this B-ALL compared to subsequent B-ALL models was its origin in the kidney-marrow, which was confirmed by successful transplantation of kidney-marrow cells of Xef1a:TEL-AML1 leukemic fish into irradiated recipients, where all transplanted recipients developed B-ALL 6-9 weeks after transplant.

\section{Key Discoveries}

- B-ALL induced by Global, but not by Lymphoblast-Specific, TEL-AML1 Expression

Sabaawy et al. showed only global expression of TEL-AML1 could induce B-ALL, with low incidence and long latency. They hypothesized that B-ALL did not occur in rag 2:hTEL-AML1 fish because TEL-AML1 was needed in less-mature stem/progenitor cells that do not yet express rag2. In fish with global expression of TEL-AML1, gene expression profiles showed deregulation of anti-apoptotic genes, such as $b c l 2, b c l-x l$, and $b a x$, which inhibit apoptosis and/or promote cell cycle arrest in HSC.

- TEL-AML1 induced Zebrafish B-ALL Resembles Human CD10 ${ }^{+}$pre-B-ALL

B-ALL in TEL-AML1 transgenic zebrafish were negative for $t c r-a$ and igm, but positive for $c d 10$, ikaros (a transcription factor expressed by lymphoid progenitors), and tal1 (a stem cell marker), which is similar to human $C D 10^{+}$pre-B-ALL [78]. A drawback of this model is its long latency and low incidence, however, these characteristics are also features of human TEL-AML1 B-ALL [79], arguably making this model a faithful reproduction of its human counterpart. Global TEL-AML1-expressing zebrafish B-ALL showed significant down-regulation of endogenous zebrafish tel. This may explain the long latency and low incidence of B-ALL in these fish, as two tel alleles would need to be disabled, rather than one (in human patients, the first TEL is disabled by the translocation itself). The expression signature they observed suggests that TEL-AML1 activity in uncommitted progenitors, but not common lymphoid progenitors, induces pre-leukemic clones that are arrested at pre-B cell stages. Then, additional acquired genetic events may allow pre-leukemic clones to proliferate and/or block apoptosis, leading to outright ALL. This sequence of events is consistent with those in TEL-AML1 B-ALL patients, where TEL-AML1-expressing progenitor cells expand prenatally as a pre-leukemic population. This provides a window for further postnatal genetic events to convert pre-leukemic progenitors into overt leukemia [80,81]. Due to the specificity of this model, it is ideally suited to study the cellular origin and the molecular pathogenesis of TEL-AML1-induced B-ALL, which represents $>20 \%$ of pediatric B-ALL [71].

\subsubsection{Model 2: B-ALL in rag2:mMyc Transgenic Zebrafish}

MYC is hyperactive in many B cell cancers [82] and MYC translocations occur in up to $7 \%$ of B-ALL [71,83,84]. In addition, B-ALL express MYC at high levels [54], and MYC overexpression is linked to relapse and refractory disease in adult B-ALL [85]. Thus, it might be expected that rag2:mMyc 
zebrafish would develop B-ALL, since B-lymphoblasts express rag2, and MYC is known to drive human B-ALL. However, although this line was first described in 2003 [32], it was only recently realized that they also develop B-ALL [86]. As noted previously, zebrafish T-ALL can be passaged by allo-transplant, facilitating study of monoclonal ALL [50]. Such studies first uncovered clonal heterogeneity in T-ALL, and then recently, distinct ALL subtypes in rag2:mMyc fish: T-ALL with short latency and high LSC frequency, and previously unrecognized B-ALL with longer latency and less LSC [50,86]. These latter cancers expressed homologues of human B-lymphoblast genes, such as rag1 and rag2, pax5, dntt (a TdT orthologue), and $c d 79 a$ (aka, Ig). In addition to known B cell markers, mMyc B-ALL also expressed gfi1ab, zfx3, notch1a, nf1b, and gtf3aa; analysis of this signature suggested up-regulation of ribosome biogenesis, RNA binding, and other biologic pathways [53].

\section{Key Discoveries}

$m M y c$ B-ALL expressed ighm constant regions, but transcripts that included recombined immunoglobulin (Ig) variable regions were not detected. Constant region mRNAs may represent 'sterile transcripts,' which mammalian B cells express during V(D)J and class switch recombination (CSR) [87-89]. The authors interpreted these data to mean that $m M y c$ B-ALL arrest at an early pro-B cell stage, prior to Ig heavy chain VDJ rearrangement [53]. The apparently lower incidence of B-ALL in $m M y c$ fish may impede studying these further, but B-ALL incidence in this line is not yet reported, so this is currently unclear. Even so, this model can potentially reveal how MYC hyperactivity transforms pro-B cells.

\subsubsection{Model 3: B-ALL in rag2:hMYC-ER Transgenic Zebrafish}

Like rag2: $m M y$ c fish, rag2:hMYC-ER fish were known to develop T-ALL [55]. However, Borga et al. recently reported B-ALL in the rag2:hMYC-ER line. They built a double-transgenic with $h M Y C$ in addition to an $l c k: E G F P$ marker transgene. Fortuitously, this marker is highly expressed by $\mathrm{T}$ cells, but lowly expressed by some-but not all—B cells [90]. Consequently, in rag2:MYC-ER;lck:EGFP fish, T-ALL are GFPhi, while B-ALL are GFPlo. This low lck expression by $h M Y C$ zebrafish B-ALL is consistent with low levels of $l c k$ in many human pre-B ALL [54]. Remarkably, many animals developed simultaneous GFP $^{\text {hi }}$ and GFPlo T- and B-ALL [54]. Histology of $h M Y C$ B-ALL demonstrated highly infiltrative disease that was indistinguishable from T-ALL (including thymic tumors), but expression patterns that were distinct from T-ALL and resembled human B-ALL [54]. $h M Y C$ B-ALL showed pre-B cell gene expression, such as igic1s1, rag2, pax5, and $c d 79 b$ [54]. Borga et al. also transplanted $h M Y C$ GFPlo B-ALL into irradiated immunosuppressed WT host fish to prove the 'immortality' $h M Y C$ B-ALL, and transplanted B-ALL remained GFP ${ }^{l o}$ and stably expressed only B-lineage markers. Borga et al. also proved that $h M Y C$ B-ALL exhibited lower LSC frequencies compared to $h M Y C$ T-ALL, mirroring $m M y c$ fish. One interesting question raised by both the $h M Y C$ and $m M y c$ models is why B-LSC are lower frequency than their T-LSC counterparts.

\section{Key Discoveries}

To date, the Borga et al. paper is the only large study of D. rerio B-ALL, as the TEL-AML1 and $m M y c$ papers presented detailed results from only five and two B-ALL, respectively. However, even with this caveat, intriguing differences between $h M Y C$ - and $m M y c$-driven B-ALL have already been recognized, suggesting these models are not interchangeable [53]. As noted above, mMyc B-ALL expressed IgM constant region transcripts. Curiously, $h M Y C$ B-ALL did not express ighm, but rather ighz, which encodes an isotype specific to fish, IgZ [53,54]. In zebrafish, isotype switching by CSR has not been described; instead, B cells "choose" between IgM and IgZ during V(D)J recombination, resulting in distinct B cell lineages [53]. Consistent with the notion of ALL in different B cell lineages, $h M Y C$ and $m M y c$ B-ALL displayed surprisingly disparate expression patterns and pathway signatures, suggesting the models are complementary. The reason(s) that transgenic $m M y c$ and $h M Y C$ (which encode $92 \%$ identical proteins) act differently in D. rerio B-lymphoblasts remain to be elucidated, but MYC's 
importance in human B-ALL warrants further investigation of this phenomenon [85,91]. The potential existence of $h M Y C$-driven GFPneg B-ALL also remains unclear, and it is possible $h M Y C$ induces B-ALL in both the IgZ- and IgM-lineages. GFPneg B cells were detected in this model, [54] but these lck negative $B$ cells have not yet been thoroughly characterized. Using alternative fluorescent reporter lines, such as $c d 79 a: E G F P$ or $c d 79 b$ :EGFP in place of lck:EGFP [92], the possibility of other B-ALL types in the $h M Y C$ model can be definitively addressed.

\section{Conclusions}

This review has highlighted published zebrafish ALL models that have contributed to our current understanding of key players and pathways in human ALL. However, D. rerio ALL models continue to emerge, with newer T- and B-ALL transgenic lines reported at recent conferences that will soon join the existing literature. Together, these vertebrate ALL models can teach us about mechanisms of ALL progression and resistance and provide platforms to screen and pre-clinically test novel pharmacologic agents. As noted throughout this review, many findings in zebrafish have been recapitulated or confirmed in human ALL samples and cell lines, or vice versa. In an era where the genetic revolution and oncology intersect ever-more-frequently, expedient and cost-effective models to survey gene function in vivo are at a premium. Going forward, zebrafish models of ALL will continue to allow us to work towards conquering this devastating disease- one fish at a time.

Author Contributions: Conceptualization, J.K.F. and A.A.S.; writing—original draft preparation, A.A.S. and G.P.; writing-review and editing, J.K.F.

Funding: J. Kimble Frazer received support from the Presbyterian Health Foundation of Oklahoma City, an INBRE pilot project award from the National Institute of General Medical Sciences (P20 GM103447), and holds the EL \& Thelma Gaylord Endowed Chair of the Children's Hospital Foundation. Arpan A. Sinha received support from the Presbyterian Health Foundation of Oklahoma City and the St. Baldrick's Foundation as a St. Baldrick's fellow.

Conflicts of Interest: The authors declare no conflict of interest.

$\begin{array}{ll}\text { Abbreviations } \\ \text { 4HT } & \text { 4-hydroxytamoxifen } \\ \text { aCGH } & \text { Array comparative genomic hybridization } \\ \text { ALL } & \text { Acute lymphoblastic leukemia } \\ \text { AML } & \text { Acute myeloid leukemia } \\ \text { B-ALL } & \text { Pre-B acute lymphoblastic leukemia } \\ \text { CAN } & \text { Copy number aberration } \\ \text { CLL } & \text { Chronic lymphocytic leukemia } \\ \text { CML } & \text { Chronic myelogenous leukemia } \\ \text { CNS } & \text { Central Nervous System } \\ \text { CSR } & \text { Class switch recombination } \\ \text { CY } & \text { Cyclophosphamide } \\ \text { D. rerio } & \text { Danio rerio } \\ \text { dpf } & \text { Days post-fertilization } \\ \text { ENU } & \text { N-ethyl- } N \text {-nitrosourea } \\ \text { ER } & \text { Estrogen receptor } \\ \text { ETP } & \text { Early Thymocyte Progenitor } \\ \text { GFP } & \text { Green fluorescent protein } \\ \text { igm } & \text { Zebrafish immunoglobulin mu } \\ \text { igz } & \text { Zebrafish immunoglobulin zeta } \\ \text { ISH } & \text { In situ hybridization } \\ \text { IVF } & \text { In-vitro fertilization } \\ \text { LIC } & \text { Leukemia-initiating cell } \\ \text { LOF } & \text { Loss of function } \\ \text { LSC } & \text { Leukemic stem cell } \\ & \end{array}$




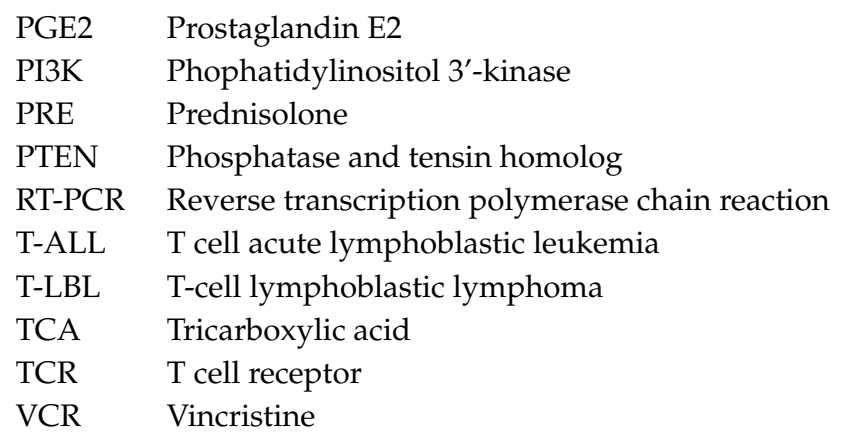

\section{References}

1. American Cancer Society. Cancer Facts \& Figures 2019. Available online: https://www.cancer.org/content/ dam/cancer-org/research/cancer-facts-and-statistics/annual-cancer-facts-and-figures/2019/cancer-factsand-figures-2019.pdf (accessed on 10 August 2019).

2. Ward, E.; DeSantis, C.; Robbins, A.; Kohler, B.; Jemal, A. Childhood and adolescent cancer statistics, 2014. CA Cancer J. Clin. 2014, 64, 83-103. [CrossRef] [PubMed]

3. Hunger, S.P.; Mullighan, C.G. Acute Lymphoblastic Leukemia in Children. N. Engl. J. Med. 2015, 373, 1541-1552. [CrossRef] [PubMed]

4. Bhojwani, D.; Yang, J.J.; Pui, C.H. Biology of childhood acute lymphoblastic leukemia. Pediatr Clin. N. Am. 2015, 62, 47-60. [CrossRef] [PubMed]

5. Curtin, S.C.; Minino, A.M.; Anderson, R.N. Declines in Cancer Death Rates Among Children and Adolescents in the United States, 1999-2014. NCHS Data Brief. 2016, 257, 1-8.

6. Locatelli, F.; Schrappe, M.; Bernardo, M.E.; Rutella, S. How I treat relapsed childhood acute lymphoblastic leukemia. Blood 2012, 120, 2807-2816. [CrossRef] [PubMed]

7. Goldberg, J.M.; Silverman, L.B.; Levy, D.E.; Dalton, V.K.; Gelber, R.D.; Lehmann, L.; Cohen, H.J.; Sallan, S.E.; Asselin, B.L. Childhood T-cell acute lymphoblastic leukemia: The Dana-Farber Cancer Institute acute lymphoblastic leukemia consortium experience. J. Clin. Oncol. 2003, 21, 3616-3622. [CrossRef]

8. Winter, S.S.; Dunsmore, K.P.; Devidas, M.; Wood, B.L.; Esiashvili, N.; Chen, Z.; Eisenberg, N.; Briegel, N.; Hayashi, R.J.; Gastier-Foster, J.M.; et al. Improved Survival for Children and Young Adults With T-Lineage Acute Lymphoblastic Leukemia: Results From the Children's Oncology Group AALL0434 Methotrexate Randomization. J. Clin. Oncol. 2018, 36, 2926-2934. [CrossRef]

9. Pui, C.H.; Carroll, W.L.; Meshinchi, S.; Arceci, R.J. Biology, risk stratification, and therapy of pediatric acute leukemias: An update. J. Clin. Oncol 2011, 29, 551-565. [CrossRef]

10. Pui, C.H.; Mullighan, C.G.; Evans, W.E.; Relling, M.V. Pediatric acute lymphoblastic leukemia: Where are we going and how do we get there? Blood 2012, 120, 1165-1174. [CrossRef]

11. Howe, K.; Clark, M.D.; Torroja, C.F.; Torrance, J.; Berthelot, C.; Muffato, M.; Collins, J.E.; Humphray, S.; McLaren, K.; Matthews, L.; et al. The zebrafish reference genome sequence and its relationship to the human genome. Nature 2013, 496, 498-503. [CrossRef]

12. Baeten, J.T.; de Jong, J.L.O. Genetic Models of Leukemia in Zebrafish. Front. Cell Dev. Biol. 2018, 6, 115. [CrossRef] [PubMed]

13. He, S.; Jing, C.B.; Look, A.T. Zebrafish models of leukemia. Methods Cell Biol. 2017, 138, 563-592. [CrossRef] [PubMed]

14. Payne, E.; Look, T. Zebrafish modelling of leukaemias. Br. J. Haematol. 2009, 146, 247-256. [CrossRef] [PubMed]

15. Squiban, B.; Frazer, J.K. Danio rerio: Small Fish Making a Big Splash in Leukemia. Curr. Pathobiol. Rep. 2014, 2, 61-73. [CrossRef]

16. Avagyan, S.; Zon, L.I. Fish to Learn: Insights into Blood Development and Blood Disorders from Zebrafish Hematopoiesis. Hum. Gene. Ther. 2016, 27, 287-294. [CrossRef]

17. Gore, A.V.; Pillay, L.M.; Venero Galanternik, M.; Weinstein, B.M. The zebrafish: A fintastic model for hematopoietic development and disease. Wiley Interdiscip. Rev. Dev. Biol. 2018, 7, e312. [CrossRef] 
18. Potts, K.S.; Bowman, T.V. Modeling Myeloid Malignancies Using Zebrafish. Front. Oncol. 2017, 7, 297. [CrossRef]

19. Rissone, A.; Burgess, S.M. Rare Genetic Blood Disease Modeling in Zebrafish. Front. Genet. 2018, 9, 348. [CrossRef]

20. Meeker, N.D.; Trede, N.S. Immunology and zebrafish: Spawning new models of human disease. Dev. Comp. Immunol. 2008, 32, 745-757. [CrossRef]

21. Lam, S.H.; Chua, H.L.; Gong, Z.; Wen, Z.; Lam, T.J.; Sin, Y.M. Morphologic transformation of the thymus in developing zebrafish. Dev. Dyn. 2002, 225, 87-94. [CrossRef]

22. Paik, E.J.; Zon, L.I. Hematopoietic development in the zebrafish. Int. J. Dev. Biol. 2010, 54, 1127-1137. [CrossRef] [PubMed]

23. Jing, L.; Zon, L.I. Zebrafish as a model for normal and malignant hematopoiesis. Dis. Model. Mech. 2011, 4, 433-438. [CrossRef] [PubMed]

24. Bentley, V.L.; Veinotte, C.J.; Corkery, D.P.; Pinder, J.B.; LeBlanc, M.A.; Bedard, K.; Weng, A.P.; Berman, J.N.; Dellaire, G. Focused chemical genomics using zebrafish xenotransplantation as a pre-clinical therapeutic platform for T-cell acute lymphoblastic leukemia. Haematologica 2015, 100, 70-76. [CrossRef] [PubMed]

25. Corkery, D.P.; Dellaire, G.; Berman, J.N. Leukaemia xenotransplantation in zebrafish-chemotherapy response assay in vivo. Br. J. Haematol. 2011, 153, 786-789. [CrossRef]

26. Veinotte, C.J.; Dellaire, G.; Berman, J.N. Hooking the big one: The potential of zebrafish xenotransplantation to reform cancer drug screening in the genomic era. Dis. Model. Mech. 2014, 7, 745-754. [CrossRef]

27. Yan, C.; Brunson, D.C.; Tang, Q.; Do, D.; Iftimia, N.A.; Moore, J.C.; Hayes, M.N.; Welker, A.M.; Garcia, E.G.; Dubash, T.D.; et al. Visualizing Engrafted Human Cancer and Therapy Responses in Immunodeficient Zebrafish. Cell 2019, 177, 1903-1914.e14. [CrossRef]

28. Pruvot, B.; Jacquel, A.; Droin, N.; Auberger, P.; Bouscary, D.; Tamburini, J.; Muller, M.; Fontenay, M.; Chluba, J.; Solary, E. Leukemic cell xenograft in zebrafish embryo for investigating drug efficacy. Haematologica 2011, 96, 612-616. [CrossRef]

29. Durinck, K.; Goossens, S.; Peirs, S.; Wallaert, A.; Van Loocke, W.; Matthijssens, F.; Pieters, T.; Milani, G.; Lammens, T.; Rondou, P.; et al. Novel biological insights in T-cell acute lymphoblastic leukemia. Exp. Hematol. 2015, 43, 625-639. [CrossRef]

30. Litzow, M.R.; Ferrando, A.A. How I treat T-cell acute lymphoblastic leukemia in adults. Blood 2015, 126, 833-841. [CrossRef]

31. Hoelzer, D.; Gokbuget, N. T-cell lymphoblastic lymphoma and T-cell acute lymphoblastic leukemia: A separate entity? Clin. Lymphoma Myeloma 2009, 9, S214-S221. [CrossRef]

32. Langenau, D.M.; Traver, D.; Ferrando, A.A.; Kutok, J.L.; Aster, J.C.; Kanki, J.P.; Lin, S.; Prochownik, E.; Trede, N.S.; Zon, L.I.; et al. Myc-induced T cell leukemia in transgenic zebrafish. Science 2003, 299, 887-890. [CrossRef] [PubMed]

33. Nilsson, J.A.; Cleveland, J.L. Myc pathways provoking cell suicide and cancer. Oncogene 2003, 22, 9007-9021. [CrossRef] [PubMed]

34. Palomero, T.; Lim, W.K.; Odom, D.T.; Sulis, M.L.; Real, P.J.; Margolin, A.; Barnes, K.C.; O’Neil, J.; Neuberg, D.; Weng, A.P.; et al. NOTCH1 directly regulates c-MYC and activates a feed-forward-loop transcriptional network promoting leukemic cell growth. Proc. Natl. Acad Sci. USA 2006, 103, 18261-18266. [CrossRef] [PubMed]

35. Sharma, V.M.; Calvo, J.A.; Draheim, K.M.; Cunningham, L.A.; Hermance, N.; Beverly, L.; Krishnamoorthy, V.; Bhasin, M.; Capobianco, A.J.; Kelliher, M.A. Notch1 contributes to mouse T-cell leukemia by directly inducing the expression of c-myc. Mol. Cell Biol. 2006, 26, 8022-8031. [CrossRef] [PubMed]

36. Weng, A.P.; Millholland, J.M.; Yashiro-Ohtani, Y.; Arcangeli, M.L.; Lau, A.; Wai, C.; Del Bianco, C.; Rodriguez, C.G.; Sai, H.; Tobias, J.; et al. c-Myc is an important direct target of Notch1 in T-cell acute lymphoblastic leukemia/lymphoma. Genes Dev. 2006, 20, 2096-2109. [CrossRef]

37. Ferrando, A.A.; Neuberg, D.S.; Staunton, J.; Loh, M.L.; Huard, C.; Raimondi, S.C.; Behm, F.G.; Pui, C.H.; Downing, J.R.; Gilliland, D.G.; et al. Gene expression signatures define novel oncogenic pathways in T cell acute lymphoblastic leukemia. Cancer Cell 2002, 1, 75-87. [CrossRef]

38. Dang, C.V. MYC on the path to cancer. Cell 2012, 149, 22-35. [CrossRef] 
39. La Starza, R.; Borga, C.; Barba, G.; Pierini, V.; Schwab, C.; Matteucci, C.; Lema Fernandez, A.G.; Leszl, A.; Cazzaniga, G.; Chiaretti, S.; et al. Genetic profile of T-cell acute lymphoblastic leukemias with MYC translocations. Blood 2014, 124, 3577-3582. [CrossRef]

40. Langenau, D.M.; Feng, H.; Berghmans, S.; Kanki, J.P.; Kutok, J.L.; Look, A.T. Cre/lox-regulated transgenic zebrafish model with conditional myc-induced T cell acute lymphoblastic leukemia. Proc. Natl. Acad Sci. USA 2005, 102, 6068-6073. [CrossRef]

41. Ferrando, A.A.; Look, A.T. Gene expression profiling in T-cell acute lymphoblastic leukemia. Semin. Hematol. 2003, 40, 274-280. [CrossRef]

42. Anderson, N.M.; Li, D.; Peng, H.L.; Laroche, F.J.; Mansour, M.R.; Gjini, E.; Aioub, M.; Helman, D.J.; Roderick, J.E.; Cheng, T.; et al. The TCA cycle transferase DLST is important for MYC-mediated leukemogenesis. Leukemia 2016, 30, 1365-1374. [CrossRef] [PubMed]

43. Mizgirev, I.V.; Revskoy, S. A new zebrafish model for experimental leukemia therapy. Cancer Biol. Ther. 2010, 9, 895-902. [CrossRef] [PubMed]

44. Smith, A.C.; Raimondi, A.R.; Salthouse, C.D.; Ignatius, M.S.; Blackburn, J.S.; Mizgirev, I.V.; Storer, N.Y.; de Jong, J.L.; Chen, A.T.; Zhou, Y.; et al. High-throughput cell transplantation establishes that tumor-initiating cells are abundant in zebrafish T-cell acute lymphoblastic leukemia. Blood 2010, 115, 3296-3303. [CrossRef] [PubMed]

45. Mizgireuv, I.V.; Revskoy, S.Y. Transplantable tumor lines generated in clonal zebrafish. Cancer Res. 2006, 66, 3120-3125. [CrossRef] [PubMed]

46. Feng, H.; Langenau, D.M.; Madge, J.A.; Quinkertz, A.; Gutierrez, A.; Neuberg, D.S.; Kanki, J.P.; Look, A.T. Heat-shock induction of T-cell lymphoma/leukaemia in conditional Cre/lox-regulated transgenic zebrafish. Br. J. Haematol. 2007, 138, 169-175. [CrossRef] [PubMed]

47. Huiting, L.N.; Samaha, Y.; Zhang, G.L.; Roderick, J.E.; Li, B.; Anderson, N.M.; Wang, Y.W.; Wang, L.; Laroche, F.; Choi, J.W.; et al. UFD1 contributes to MYC-mediated leukemia aggressiveness through suppression of the proapoptotic unfolded protein response. Leukemia 2018, 32, 2339-2351. [CrossRef] [PubMed]

48. Feng, H.; Stachura, D.L.; White, R.M.; Gutierrez, A.; Zhang, L.; Sanda, T.; Jette, C.A.; Testa, J.R.; Neuberg, D.S.; Langenau, D.M.; et al. T-lymphoblastic lymphoma cells express high levels of BCL2, S1P1, and ICAM1, leading to a blockade of tumor cell intravasation. Cancer Cell 2010, 18, 353-366. [CrossRef]

49. Langenau, D.M.; Keefe, M.D.; Storer, N.Y.; Jette, C.A.; Smith, A.C.; Ceol, C.J.; Bourque, C.; Look, A.T.; Zon, L.I. Co-injection strategies to modify radiation sensitivity and tumor initiation in transgenic Zebrafish. Oncogene 2008, 27, 4242-4248. [CrossRef]

50. Blackburn, J.S.; Liu, S.; Wilder, J.L.; Dobrinski, K.P.; Lobbardi, R.; Moore, F.E.; Martinez, S.A.; Chen, E.Y.; Lee, C.; Langenau, D.M. Clonal evolution enhances leukemia-propagating cell frequency in T cell acute lymphoblastic leukemia through Akt/mTORC1 pathway activation. Cancer Cell 2014, 25, 366-378. [CrossRef]

51. Gutierrez, A.; Sanda, T.; Grebliunaite, R.; Carracedo, A.; Salmena, L.; Ahn, Y.; Dahlberg, S.; Neuberg, D.; Moreau, L.A.; Winter, S.S.; et al. High frequency of PTEN, PI3K, and AKT abnormalities in T-cell acute lymphoblastic leukemia. Blood 2009, 114, 647-650. [CrossRef]

52. Palomero, T.; Dominguez, M.; Ferrando, A.A. The role of the PTEN/AKT Pathway in NOTCH1-induced leukemia. Cell Cycle 2008, 7, 965-970. [CrossRef] [PubMed]

53. Borga, C.; Foster, C.A.; Iyer, S.; Garcia, S.P.; Langenau, D.M.; Frazer, J.K. Molecularly distinct models of zebrafish Myc-induced B cell leukemia. Leukemia 2019, 33, 559-562. [CrossRef] [PubMed]

54. Borga, C.; Park, G.; Foster, C.; Burroughs-Garcia, J.; Marchesin, M.; Shah, R.; Hasan, A.; Ahmed, S.T.; Bresolin, S.; Batchelor, L.; et al. Simultaneous B and T cell acute lymphoblastic leukemias in zebrafish driven by transgenic MYC: Implications for oncogenesis and lymphopoiesis. Leukemia 2019, 33, 333-347. [CrossRef] [PubMed]

55. Gutierrez, A.; Grebliunaite, R.; Feng, H.; Kozakewich, E.; Zhu, S.; Guo, F.; Payne, E.; Mansour, M.; Dahlberg, S.E.; Neuberg, D.S.; et al. Pten mediates Myc oncogene dependence in a conditional zebrafish model of T cell acute lymphoblastic leukemia. J. Exp. Med. 2011, 208, 1595-1603. [CrossRef]

56. Reynolds, C.; Roderick, J.E.; LaBelle, J.L.; Bird, G.; Mathieu, R.; Bodaar, K.; Colon, D.; Pyati, U.; Stevenson, K.E.; Qi, J.; et al. Repression of BIM mediates survival signaling by MYC and AKT in high-risk T-cell acute lymphoblastic leukemia. Leukemia 2014, 28, 1819-1827. [CrossRef] 
57. Gutierrez, A.; Pan, L.; Groen, R.W.; Baleydier, F.; Kentsis, A.; Marineau, J.; Grebliunaite, R.; Kozakewich, E.; Reed, C.; Pflumio, F.; et al. Phenothiazines induce PP2A-mediated apoptosis in T cell acute lymphoblastic leukemia. J. Clin. Investig. 2014, 124, 644-655. [CrossRef]

58. Weng, A.P.; Ferrando, A.A.; Lee, W.; Morris, J.P.t.; Silverman, L.B.; Sanchez-Irizarry, C.; Blacklow, S.C.; Look, A.T.; Aster, J.C. Activating mutations of NOTCH1 in human T cell acute lymphoblastic leukemia. Science 2004, 306, 269-271. [CrossRef]

59. Chen, J.; Jette, C.; Kanki, J.P.; Aster, J.C.; Look, A.T.; Griffin, J.D. NOTCH1-induced T-cell leukemia in transgenic zebrafish. Leukemia 2007, 21, 462-471. [CrossRef]

60. Blackburn, J.S.; Liu, S.; Raiser, D.M.; Martinez, S.A.; Feng, H.; Meeker, N.D.; Gentry, J.; Neuberg, D.; Look, A.T.; Ramaswamy, S.; et al. Notch signaling expands a pre-malignant pool of T-cell acute lymphoblastic leukemia clones without affecting leukemia-propagating cell frequency. Leukemia 2012, 26, 2069-2078. [CrossRef]

61. Sanchez-Martin, M.; Ferrando, A. The NOTCH1-MYC highway toward T-cell acute lymphoblastic leukemia. Blood 2017, 129, 1124-1133. [CrossRef]

62. Herranz, D.; Ambesi-Impiombato, A.; Palomero, T.; Schnell, S.A.; Belver, L.; Wendorff, A.A.; Xu, L.; Castillo-Martin, M.; Llobet-Navas, D.; Cordon-Cardo, C.; et al. A NOTCH1-driven MYC enhancer promotes T cell development, transformation and acute lymphoblastic leukemia. Nat. Med. 2014, 20, 1130-1137. [CrossRef] [PubMed]

63. Frazer, J.K.; Meeker, N.D.; Rudner, L.; Bradley, D.F.; Smith, A.C.; Demarest, B.; Joshi, D.; Locke, E.E.; Hutchinson, S.A.; Tripp, S.; et al. Heritable T-cell malignancy models established in a zebrafish phenotypic screen. Leukemia 2009, 23, 1825-1835. [CrossRef] [PubMed]

64. Langenau, D.M.; Ferrando, A.A.; Traver, D.; Kutok, J.L.; Hezel, J.P.; Kanki, J.P.; Zon, L.I.; Look, A.T.; Trede, N.S. In vivo tracking of T cell development, ablation, and engraftment in transgenic zebrafish. Proc. Natl. Acad. Sci. USA 2004, 101, 7369-7374. [CrossRef] [PubMed]

65. Rudner, L.A.; Brown, K.H.; Dobrinski, K.P.; Bradley, D.F.; Garcia, M.I.; Smith, A.C.; Downie, J.M.; Meeker, N.D.; Look, A.T.; Downing, J.R.; et al. Shared acquired genomic changes in zebrafish and human T-ALL. Oncogene 2011, 30, 4289-4296. [CrossRef] [PubMed]

66. Leong, W.Z.; Tan, S.H.; Ngoc, P.C.T.; Amanda, S.; Yam, A.W.Y.; Liau, W.S.; Gong, Z.; Lawton, L.N.; Tenen, D.G.; Sanda, T. ARID5B as a critical downstream target of the TAL1 complex that activates the oncogenic transcriptional program and promotes T-cell leukemogenesis. Genes Dev. 2017, 31, 2343-2360. [CrossRef]

67. Mansour, M.R.; He, S.; Li, Z.; Lobbardi, R.; Abraham, B.J.; Hug, C.; Rahman, S.; Leon, T.E.; Kuang, Y.Y.; Zimmerman, M.W.; et al. JDP2: An oncogenic bZIP transcription factor in T cell acute lymphoblastic leukemia. J. Exp. Med. 2018, 215, 1929-1945. [CrossRef]

68. Mullighan, C.G. Molecular genetics of B-precursor acute lymphoblastic leukemia. J. Clin. Investig. 2012, 122, 3407-3415. [CrossRef]

69. Terwilliger, T.; Abdul-Hay, M. Acute lymphoblastic leukemia: A comprehensive review and 2017 update. Blood Cancer J. 2017, 7, e577. [CrossRef]

70. Chiang, M.Y.; Wang, Q.; Gormley, A.C.; Stein, S.J.; Xu, L.; Shestova, O.; Aster, J.C.; Pear, W.S. High selective pressure for Notch1 mutations that induce Myc in T-cell acute lymphoblastic leukemia. Blood 2016, 128, 2229-2240. [CrossRef]

71. Gu, Z.; Churchman, M.L.; Roberts, K.G.; Moore, I.; Zhou, X.; Nakitandwe, J.; Hagiwara, K.; Pelletier, S.; Gingras, S.; Berns, H.; et al. PAX5-driven subtypes of B-progenitor acute lymphoblastic leukemia. Nat. Genet. 2019, 51, 296-307. [CrossRef]

72. Lilljebjorn, H.; Henningsson, R.; Hyrenius-Wittsten, A.; Olsson, L.; Orsmark-Pietras, C.; von Palffy, S.; Askmyr, M.; Rissler, M.; Schrappe, M.; Cario, G.; et al. Identification of ETV6-RUNX1-like and DUX4-rearranged subtypes in paediatric B-cell precursor acute lymphoblastic leukaemia. Nat. Commun 2016, 7, 11790. [CrossRef] [PubMed]

73. Lilljebjorn, H.; Fioretos, T. New oncogenic subtypes in pediatric B-cell precursor acute lymphoblastic leukemia. Blood 2017, 130, 1395-1401. [CrossRef]

74. Tamai, H.; Miyake, K.; Takatori, M.; Miyake, N.; Yamaguchi, H.; Dan, K.; Shimada, T.; Inokuchi, K. Activated K-Ras protein accelerates human MLL/AF4-induced leukemo-lymphomogenicity in a transgenic mouse model. Leukemia 2011, 25, 888-891. [CrossRef] [PubMed] 
75. Jacoby, E.; Chien, C.D.; Fry, T.J. Murine models of acute leukemia: Important tools in current pediatric leukemia research. Front. Oncol. 2014, 4, 95. [CrossRef] [PubMed]

76. Krivtsov, A.V.; Feng, Z.; Lemieux, M.E.; Faber, J.; Vempati, S.; Sinha, A.U.; Xia, X.; Jesneck, J.; Bracken, A.P.; Silverman, L.B.; et al. H3K79 methylation profiles define murine and human MLL-AF4 leukemias. Cancer Cell 2008, 14, 355-368. [CrossRef] [PubMed]

77. Trede, N.S.; Langenau, D.M.; Traver, D.; Look, A.T.; Zon, L.I. The use of zebrafish to understand immunity. Immunity 2004, 20, 367-379. [CrossRef]

78. Sabaawy, H.E.; Azuma, M.; Embree, L.J.; Tsai, H.J.; Starost, M.F.; Hickstein, D.D. TEL-AML1 transgenic zebrafish model of precursor B cell acute lymphoblastic leukemia. Proc. Natl. Acad Sci. USA 2006, 103, 15166-15171. [CrossRef]

79. Wiemels, J.L.; Ford, A.M.; Van Wering, E.R.; Postma, A.; Greaves, M. Protracted and variable latency of acute lymphoblastic leukemia after TEL-AML1 gene fusion in utero. Blood 1999, 94, 1057-1062. [CrossRef]

80. Tsuzuki, S.; Seto, M. TEL (ETV6)-AML1 (RUNX1) initiates self-renewing fetal pro-B cells in association with a transcriptional program shared with embryonic stem cells in mice. Stem Cells 2013, 31, 236-247. [CrossRef]

81. Greaves, M.F.; Maia, A.T.; Wiemels, J.L.; Ford, A.M. Leukemia in twins: Lessons in natural history. Blood 2003, 102, 2321-2333. [CrossRef]

82. Raess, P.W.; Moore, S.R.; Cascio, M.J.; Dunlap, J.; Fan, G.; Gatter, K.; Olson, S.B.; Braziel, R.M. MYC immunohistochemical and cytogenetic analysis are required for identification of clinically relevant aggressive B cell lymphoma subtypes. Leuk Lymphoma 2018, 59, 1391-1398. [CrossRef] [PubMed]

83. Navid, F.; Mosijczuk, A.D.; Head, D.R.; Borowitz, M.J.; Carroll, A.J.; Brandt, J.M.; Link, M.P.; Rozans, M.K.; Thomas, G.A.; Schwenn, M.R.; et al. Acute lymphoblastic leukemia with the (8;14)(q24;q32) translocation and FAB L3 morphology associated with a B-precursor immunophenotype: The Pediatric Oncology Group experience. Leukemia 1999, 13, 135-141. [CrossRef] [PubMed]

84. Moorman, A.V.; Chilton, L.; Wilkinson, J.; Ensor, H.M.; Bown, N.; Proctor, S.J. A population-based cytogenetic study of adults with acute lymphoblastic leukemia. Blood 2010, 115, 206-214. [CrossRef] [PubMed]

85. Allen, A.; Gill, K.; Hoehn, D.; Sulis, M.; Bhagat, G.; Alobeid, B. C-myc protein expression in B-cell acute lymphoblastic leukemia, prognostic significance? Leuk. Res. 2014, 38, 1061-1066. [CrossRef] [PubMed]

86. Garcia, E.G.; Iyer, S.; Garcia, S.P.; Loontiens, S.; Sadreyev, R.I.; Speleman, F.; Langenau, D.M. Cell of origin dictates aggression and stem cell number in acute lymphoblastic leukemia. Leukemia 2018, 32, 1860-1865. [CrossRef]

87. Ono, M.; Nose, M. Persistent expression of an unproductive immunoglobulin heavy chain allele with DH-JH-gamma configuration in peripheral tissues. APMIS 2007, 115, 1350-1356. [CrossRef]

88. Nelson, K.J.; Haimovich, J.; Perry, R.P. Characterization of productive and sterile transcripts from the immunoglobulin heavy-chain locus: Processing of micron and muS mRNA. Mol. Cell Biol. 1983, 3, 1317-1332. [CrossRef]

89. Neale, G.A.; Kitchingman, G.R. mRNA transcripts initiating within the human immunoglobulin mu heavy chain enhancer region contain a non-translatable exon and are extremely heterogeneous at the $5^{\prime}$ end. Nucleic Acids Res. 1991, 19, 2427-2433. [CrossRef]

90. Burroughs-Garcia, J.; Hasan, A.; Park, G.; Borga, C.; Frazer, J.K. Isolating Malignant and Non-Malignant B Cells from lck:eGFP Zebrafish. J. Vis. Exp. 2019. [CrossRef]

91. Kohrer, S.; Havranek, O.; Seyfried, F.; Hurtz, C.; Coffey, G.P.; Kim, E.; Ten Hacken, E.; Jager, U.; Vanura, K.; O'Brien, S.; et al. Pre-BCR signaling in precursor B-cell acute lymphoblastic leukemia regulates PI3K/AKT, FOXO1 and MYC, and can be targeted by SYK inhibition. Leukemia 2016, 30, 1246-1254. [CrossRef]

92. Liu, X.; Li, Y.S.; Shinton, S.A.; Rhodes, J.; Tang, L.; Feng, H.; Jette, C.A.; Look, A.T.; Hayakawa, K.; Hardy, R.R. Zebrafish B Cell Development without a Pre-B Cell Stage, Revealed by CD79 Fluorescence Reporter Transgenes. J. Immunol. 2017, 199, 1706-1715. [CrossRef] [PubMed]

(C) 2019 by the authors. Licensee MDPI, Basel, Switzerland. This article is an open access article distributed under the terms and conditions of the Creative Commons Attribution (CC BY) license (http://creativecommons.org/licenses/by/4.0/). 